\title{
Syrien im 1.-7. Jahrhundert nach Christus
}

Akten der 1. Tübinger Tagung zum Christlichen Orient (15.-16. Juni 2007)

Hrsg. v. Dmitrij Bumazhnov u. Hans R. Seeliger

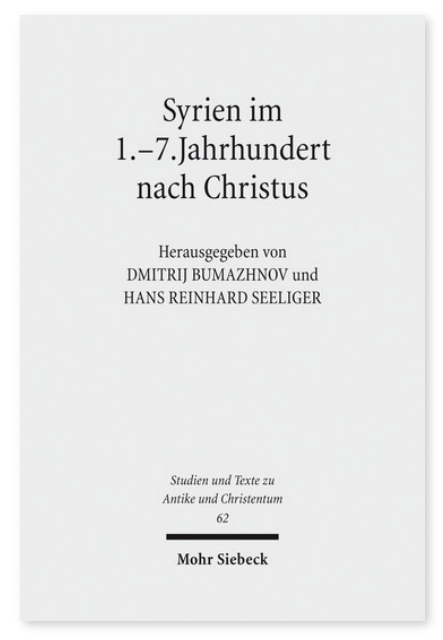

2011. VIII, 284 Seiten. STAC 62

ISBN 978-3-16-151764-8 DOI 10.1628/978-3-16-151764-8 eBook PDF 74,00€

ISBN 978-3-16-151000-7 fadengeheftete Broschur 74,00€
Die Beiträge dieses Konferenzbandes umfassen die Entwicklung des syrischen Christentums seit dem 1. Jahrhundert nach Chr. bis in die frühe islamische Zeit. Die Aufsätze setzen thematisch bei den Syrern im Neuen Testament an und behandeln Fragen nach den Anfängen der syrischen asketischen Bewegung, der Geschichte der Bischofssitze in West- und Ostsyrien sowie nach den syrischen Quellen des arabischen Christentums und Judentums. Sie befassen sich mit der Theologie des Geistes Gottes bei den Ost-Syrern, dem Martyrium der Mimen und der »syrischen Masora«, einer Neuinterpretation des Perlenliedes.

Mit Beiträgen von:

Luise Abramowski, Yuri Arzhanov, Dmitrij F. Bumazhnov, Till Engelmann, Heinz Gaube, Cornelia Horn, Nestor Kavvadas, Jonathan Loopstra, Anna Maria Schwemer, Hans Reinhard Seeliger, Felix Thome, Jürgen Tubach

Inhaltsübersicht

Luise Abramowski : Der Bischof von Seleukia-Ktesiphon als Katholikos und Patriarch der Kirche des Ostens - Yuri Arzhanov: Syrische Quellen zur Geschichte des Christentums und des Judentums im vorislamischen Südarabien - Dmitrij F. Bumazhnov : Qyāmā before Aphrahat. The Development of the Idea of Covenant in Some Early Syriac Documents - Till Engelmann : Monastisch geprägter Theologe oder theologisch gebildeter Mönch? Das Zentrum der Theologie Babais des Großen - Heinz Gaube: The Umayyad »Desert Castles«. Some political and economical considerations concerning their origin - Cornelia Horn: Women, Prostitution, and Violence in the Syriac Martyrdom of the Mimes - Nestor Kavvadas: Der Geist Gottes und die Vergöttlichung des Menschen bei Isaak von Ninive - Jonathan Loopstra: Jacob of Edessa and Patristic Collections in the "Syriac Masora«: Some Soundings - Anna Maria Schwemer: Die ersten Christen in Syrien - Hans Reinhard Seeliger: Die Erforschung der spätantiken Bischofssitze des syrisch-palästinischen Raumes und ihrer Bauten - Felix Thome: Gottes Liebe zur verlorenen Menschheit. Die Abrahamerzählung in der Auslegung Narsais von Edessa - Jürgen Tubach : Zur Interpretation des Perlenliedes. Exegetische Prämissen und ihre Schlussfolgerungen

Dmitrij Bumazhnov Geboren 1967; Studium der Klassischen Philologie an der Universität St. Petersburg; 2001 Promotion in "Sprachen und Kulturen des Christlichen Orients « Tübingen; 2008 Habilitation für das gleiche Fach in Tübingen; seit 2011 Mitglied des Forschungszentrums EDRIS, Göttingen.

Hans Reinhard Seeliger Geboren 1950; o. Prof. für Alte Kirchengeschichte, Patrologie und Christliche Archäologie an der Katholisch-Theologischen Fakultät der Universität Tübingen.

Jetzt bestellen:

https://mohrsiebeck.com/buch/syrien-im-1-7-jahrhundert-nach-christus-9783161517648?no_cache=1 order@mohrsiebeck.com

Telefon: $+49(0) 7071-923-17$

Telefax: $+49(0) 7071-51104$ 